\title{
An application of the ADAPT-ITT model to an evidence-based behavioral HIV prevention intervention for men who have sex with men in Ghana
}

\author{
Descriptive article \\ Gamji M'Rabiu Abubakari ${ }^{1}$, DeAnne Turner' ${ }^{2}$ LaRon E. Nelson ${ }^{1-4}$, Apondi Judith Odhiambo ${ }^{5}$, Francis Boakye ${ }^{6}$, Adom \\ Manu $^{7}$, Kwasi Torpey ${ }^{7}$, Leo Wilton ${ }^{8,9}$ \\ ${ }^{1}$ Center for Interdisciplinary Research on AIDS, School of Public Health/Medicine, New Haven, CT, USA; ${ }^{2}$ Yale \\ University School of Nursing, New Haven, CT, USA; ${ }^{3}$ Yale Institute of Global Health, Yale University, New haven, CT, \\ USA; ${ }^{4}$ MAP Center for Urban Health Solutions, Unity Health Toronto, Toronto, Canada; ${ }^{5}$ Dalla Lana School of Public \\ Health, University of Toronto, Toronto, Canada; ${ }^{6}$ Priorities on Rights and Sexual Health, Accra, Ghana; ${ }^{7}$ University of \\ Ghana School of Public Health, Accra, Ghana; ${ }^{8}$ Department of Human Development, State University of New York at \\ Binghamton, Binghamton, New York USA; ${ }^{9}$ Faculty of Humanities, University of Johannesburg, Johannesburg, South \\ Africa
}

Corresponding author: G.M’R Abubakari (mohammed-rabiu.abubakari@yale.edu)

\section{ABSTRACT}

Despite constituting only about $1 \%$ of Ghana's population, men who have sex with men (MSM) carry a disproportionate burden of HIV infections, constituting $18 \%$ of the population of people living with HIV in the country. Scholars have associated the disproportionate infection rates of HIV among MSM with existing structural factors (such as criminalization and stigma against MSM), and individual-level factors (such as sex without a condom, and transactional sex). Nonetheless, only a few scholars consider intervention as an approach to reducing HIV and other STD risk among MSM in the country. As such, in collaboration with community partners, we engaged MSM through the use of the ADAPT-ITT model to adapt the Many Men Many Voices (3MV) to address the needs of MSM. We addressed STD risk factors and ways to reduce HIV infections. In this paper, we describe the use of the ADAPTITT model in the adoption and adaptation of the 3MV with MSM in Ghana. Whereas the 3MV was a good fit for our target population, we made modifications to fit the Ghanaian cultural setting by examining HIV and other STD risk in the context of bisexuality, insisting on discretion in choosing our location, and on incorporating a historical colonial setting in contextualizing sexuality and stigma in the Ghanaian sociocultural context. Our implementation process shows the efficacy of collaboration with community partners to implement culturally relevant interventions in HIV and STD prevention efforts in highly stigmatized environments.

\section{KEYWORDS}

ADAPT-ITT, Community Participatory Research, Ghana, HIV/STD, Implementation Science, Many-Men-Many-Voice $-3 M V, M S M$

\section{INTRODUCTION}

The United Nations Program on HIV and AIDS (UNAIDS) aims to eradicate human immunodeficiency virus (HIV) among member countries by 2030, yet several African countries face pervasive challenges in reducing the HIV incidence (Poku, 2016; Joint United Nations Programme on HIV/AIDS, 2014). In 2019, the estimated national prevalence rate of HIV in Ghana was about $2 \%$, representing 342, 307 individuals living with HIV (Ghana AIDS Commission, 2020). Whereas Ghana recorded some progress in reducing HIV infections, the MSM population remains disproportionately affected and at high risk as 
compared to the general population (Ghana AIDS Commission, 2020). Despite constituting only $1 \%$ of Ghana's population, the most recent Ghana Men Study Report show that MSM account for $18.1 \%$ of people living with HIV in the country with regional rates ranging from $42.2 \%$ in greater Accra to 4.3 in Northern Ghana (GAC, 2017).

However, prior studies have predominately shown that MSM in Ghana and Africa experience high levels of stigma and discrimination due to sexual orientation, social isolation, HIV status, and gender non-conformity (Caroll \& Itaborahy, 2015; Kushwaha et al., 2017; Nelson et al., 2016). Each of these stigmas alone impacts HIV testing and access to care, however, together they produce an even greater impact on the health of Ghanaian MSM (Kushwaha et al, 2017; Nelson et al, 2016; Girault et al., 2015). These stigmas originating from community members, family, friends, and even health care providers, and law enforcement affect MSM confidence in disclosing their sexuality and engaging with HIV prevention and care services (Kushwaha et al., 2017; Nelson et al., 2016; Girault et al., 2015; Abubakari et al., 2020; Nelson et al., 2015; Nyblade et al., 2017; Ogunbajo et al., 2018). For instance, some MSM reported that when healthcare providers realize they engage in same-sex activities, they say that it is against religion and culture (Kushwaha et al., 2017; Abubakari et al., 2020). Consequentially, MSM remain challenged with HIV risk factors such as inconsistent condom use during sexual intercourse, substance use, multiple sexual partners and the disproportionate burden of HIV infections (GAC, 2017; Kushwaha et al., 2017; Nelson et al., 2015; Evans et al., 2016).

Whereas previous studies have attempted to understand the conditions and HIV risk factors among MSM in the country, such studies fail to address the complexities of issues that affect MSM and to provide interventions that address the needs of the MSM community (Kushwaha et al., 2017; Nelson et al., 2015). To account for this gap, our team identified the Many Men Many Voices (3MV) as an appropriate intervention that can be adapted for implementation among Ghana MSM.

\section{Many men, many voices (3MV)}

The $3 \mathrm{MV}$ is a seven-session group-based HIV prevention intervention designed for black gay, bisexual, and other men who have sex with men
(MSM) (Wilton et al., 2019). The program incorporates social and cultural norms and addresses the effects of racism and homophobia. Specifically, it aims at increasing condom use, reducing the number of sex partners, increasing HIV and other STD testing, enhancing MSM self-esteem on sexual and racial identity, building a menu of behavioral options for HIV and other STD risk reduction, and providing social support (Abubakari et al., 2020; Wilton et al., 2009). Details of the $3 \mathrm{MV}$ specific sessions in the context of our adaptation are outlined elsewhere (Abubakari et al., 2020).

\section{The ADAPT-ITT}

To adapt the $3 \mathrm{MV}$ to fit the Ghanaian context, we used the ADAPT-ITT model (Table 1), an eight-phase process used to inform the adoption and adaptation of evidence-based interventions for populations and contexts (Wingwood et al., 2011a; Wingwood et al., 2008; Wingwood et al., 2011b). The model was developed based on a need to appropriately adapt interventions, initially in the field of HIV, while maintaining the theoretical premise and core components of the original efficacious intervention (Wingwood et al., 2011a; Wingwood et al., 2008; Wingwood et al., 2011b). The model begins with assessing the needs and experiences of the new target population (Assessment), deciding on an intervention to be adopted (Decision), pretesting the original intervention via theatre testing with the new target population to assess the changes needed for content and delivery (Adaptation), producing a draft intervention manual (Production), identifying topical experts to review and provide feedback to the revised manual (Topical Expert), integrating this feedback (Integration), training staff to administer the new intervention (Training), and pilot testing the intervention (Testing) (Wingwood et al., 2011a; Wingwood et al., 2008; Wingwood et al., 2011b).

The ADAPT-ITT model has been used within the United States and internationally to culturally adapt evidence-based interventions (Wingwood et al., 2011a; Wingwood et al., 2008; Wingwood et al., 2011b; Pan et al., 2020). Although primarily developed in the field of HIV, the model has also been used to adapt interventions addressing a variety of fields, such as substance use disorders and mental health (Druss et al., 2010; Satinsky et al., 2020; Latham et al., 2020; Marhefka et al., 2014; Sullivan et al., 2014; Craig Rushing et al., 2016; Audet et al., 2017; Bere et al., 2017; Chen et al., 2013; Haynes et al., 
2014; Saleh-Onoya et al., 2008). Within the field of HIV, the ADAPT-ITT model has been used in the adaptation of interventions in HIV risk reduction, HIV prevention, HIV testing, counseling, and treatment adherence (Latham et al., 2020; Marhefka et al., 2014; Sullivan et al., 2014; Craig Rushing et al., 2016; Audet et al., 2017; Bere et al., 2017). A variety of models can be used for program adaptation (Chen et al., 2013; Haynes et al., 2014; Saleh-Onoya et al., 2008; Hohmeier et al., 2019). However, the ADAPTITT model is unique among other adaptation models as it utilizes triangulation, directly includes participation from the targeted population and stakeholders and provides a systematic approach to guide the program adaptation (Card et al., 2011; Cederbaum et al., 2014; Knight et al., 2014; Escoffery et al., 2019; Escoffery et al., 2018). This iterative, community-driven adaptation positions the model to be useful in addressing the needs of MSM in Ghana. In this paper, we describe the use of the ADAPT-ITT model in the adoption and adaptation of the $3 \mathrm{MV}$ into Nyansapo to address the diverse needs of men who have sex with men in Ghana.

\section{METHODS AND RESULTS}

\section{Adaptation of the $3 \mathrm{MV}$ into the Nyansapo intervention using the ADAPT-ITT framework}

\section{Phase 1: Assessment}

The assessment phase typically includes an initial data collection to examine the priorities of the target population that will participate in the intervention. The intervention team also examines the capacity of the implementing organization to manage and execute an intervention to the benefit of the target population (Wingwood et al., 2011a; Wingwood et al., 2008).

Procedures and findings. The lead organization, Priorities on Rights and Sexual Health (PORSH), in Ghana, is a non-governmental organization (NGO) concerned with sexual health of MSM in Ghana. MSM that work with PORSH provided feedback on the need for an intervention that addresses the specific needs of MSM as previous research among MSM were largely epidemiological. The MSM identified the need for interventions that provide them the necessary know-how to confront some of their challenges such as understanding sexuality, gender norms, HIV risk, and harm reduction strategies. Discussion among the staff of the organization and the Principal Investigator (PI), as well as a review of the content of previous research in Ghana, were conducted to help shape the direction of an intervention that will meet the priorities of the participants. Thus, the lead investigators examined the 3MV intervention as appropriate to meet the needs of Ghanaian MSM. Based on the scope of the organization, the team assessed the capacity of the staff to implement the $3 \mathrm{MV}$ intervention. We examined the knowledge of the staff on the subject matter and their ability to recruit, organize, and effectively deliver the program.

Reports from previous studies supported the need for intervention among the MSM in Ghana; they have a disproportionate prevalence of HIV compared to the general population and other key populations such as the sex workers. They also report high existence of stigma and low understanding of gender and sexual identity and related risk. MSM in Ghana did not have a clear understanding of homosexual identity and bisexuality, and the kind of risk associated with positions during penetrative sex. PORSH had the capabilities to implement an intervention because the staff identify as MSM and understand MSM lived experiences (Kushwaha et al., 2017; Nelson et al., 2015).

Modifications/actions. Whereas $3 \mathrm{MV}$ was identified as an appropriate intervention, modifications were not carried out at this stage. Instead of the typical research procedure where needs are assessed as part of the model adapted, our assessment was based on deliberations with the community partners and review of the previous studies conducted by the team among MSM in the country.

\section{Phase 2: Decision}

The Decision phase of the ADAPT-ITT model includes selecting an applicable intervention to be adopted or adapted based on community needs. If adaptation is required, initial aspects to be adapted are noted (Wilton et al., 2009; Wingwood et al., 2009; Wingwood et al., 2011a; Wingwood et al., 2008; Wingwood et all., 2011b).

Procedures and findings. As indicated in the assessment stage, the decision-making process occurred via iterative conversations between the study PI and members of PORSH in Accra, Ghana. The 
community partners agreed that $3 \mathrm{MV}$ meets the scope of the intervention needed as it can be tailored to fit the Ghanaian cultural setting in the modification stages. Ghanaian team members identified the need for an alteration to focus on gender and sexual identity among MSM in Ghana. They also sought maintenance of the $3 \mathrm{MV}$ focus on health-seeking behaviors but also for a holistic focus that will address the lived experiences of Ghanaian MSM, rather than solely sexual behavior (Table 2).

Modifications/actions. Intervention needs and considerations. The $3 \mathrm{MV}$ is a CDC identified evidencebased intervention that also meets the criteria identified by the Ghanaian team. Hence, the study PI sent the $3 \mathrm{MV}$ intervention manual to the Ghanaian team for review. As shown in Table 2, the goals of the $3 \mathrm{MV}$ did not change as they fit with the objectives of the identified exigencies in Ghana. However, modifications were made to content areas to fit the Ghana cultural context.

Adaptations needed. A historical component was added to connect the history of colonialism, religion, the criminalization of same-sex sexual acts, and the stigma attached to MSM in Ghana. A historical sitevisit to Elmina Castle (castle and slave dungeons where slaves were housed and transported by the colonial masters) was included to provide a symbolic overview of colonialism and its accompanying factors such as religion, anti-gay sentiments, and thoughts on abandoning or holding on to such colonial impacts on perceptions and social norms. The team also agreed to focus more on bisexual identity due to the prevalence of bisexuality among Ghanaian MSM. The adopted intervention was named Nyansapo (refers to wisdom in achieving a goal in the language of Twi) to also reflect the Ghanaian fabric. Two facilitators were trained on $3 \mathrm{MV}$ to ensure that they were fully capable of group facilitation and delivering the intervention.

\section{Phase 3: Adaptation}

The adaptation phase of the ADAPT-IT model is about pre-testing the intervention with the target population to ascertain their thoughts about the intervention, mobilize feedback on the format and content of the intervention, and receive recommendations for improving the acceptability of the intervention among the target audience (Sullivan et al., 2014). In our implementation, this phase was completed in partnership with the Ghana team.
Procedure and findings. The designated facilitators traveled from Ghana to the United States for training on the various components of the 3MV. During the training, trainers and trainees iteratively identified key areas that required modifications and collected feedback and recommendations on the intervention. It was commonly agreed that no major modifications to the intervention were needed as the adaption needed to remain true to the intervention goals. However, there was an increased need to adjust the intervention to socio-historical contexts related to colonialism, religion, and Ghanaian cultural values and worldviews. There was also a reiterated need for discussions on bisexuality.

Modification/action. Minor modifications focusing on culture, language, ethnicity, cultural groups, and religions were reinforced as necessary to fit the Ghana socio-cultural context. The modifications also provided attention to social issues such as law enforcement and violence. This was important because MSM in Ghana often face physical and verbal violence from community members. Due to the criminalization of homosexuality in the country, MSM do not often report abuse to law enforcement due to the fear of stigma. Discussions continued on the integration of local language in identifying MSM and bisexuality and related risks due to the prevalence of bisexuality in Ghana.

\section{Phase 4: Production}

The phase of production includes creating the material needed for the program (Sullivan et al., 2014). For the modified 3MV (Nyansapo) intervention, the phase included the creation of the Nyansapo manual that corresponds to the 3MV intervention, and supplemental materials to support the content areas.

Procedure and findings. As discussed in earlier stages, the team assessed the 3MV to check its suitability for adaptation into Nyansapo sites and also assessed the suitability for hosting the MSM during the three-day intervention. We examined sites for the following considerations: room capacity, privacy, transportation, security, and nearness to risks such as a religious body, or a popular spot such as a club. Such considerations were crucial due to the need to conceal the identity of participants, and to limit their exposure to danger or community reaction. Due to a 
lack of acceptance, MSM in Ghana remain hidden and are not comfortable in easily accessible or highly visible settings. A site (an isolated beach resort) was chosen in the central region of Ghana, and a manual was created for implementation during the intervention.

Modification/action. The Nyansapo manual was created with detailed activities for subject areas of the $3 \mathrm{MV}$. The new manual was designed to take into account the modifications identified to include the historical context of the criminalization of homosexuality, and sexual identity.

\section{Phases 5 and 6: Topical Experts and feedback integration}

The Topical Experts phase consisted of identifying content experts related to the intervention (Sullivan et al., 2014).

Procedures and findings. During the study, three scholars with expertise in HIV prevention and care research and community engagement among MSM were identified.

Modification/action. No modifications were made during these phases as we involved the relevant experts from the outset of the Nyansapo manual design. However, they recommended the integration of graduation and certification components to the intervention. All MSM who participated in the training attended a graduation ceremony and were presented with certificates to show that they understood the complexity of HIV and STD risk and prevention processes.

\section{Phase 7: Training}

The training process involved, a three-day training of co-facilitators and assistants on how to deliver the adapted 3MV intervention (Nyansapo) (Sullivan et al., 2014). The training was conducted by facilitators who went to the original $3 \mathrm{MV}$ training in the US. The training of co-facilitators and assistants aimed at ensuring buy-in and engagement in implementing the intervention. It also focused on developing skills and practicing the delivery of the intervention, including updating and refining the training materials. Our initial adaptation emphasized the importance of focusing on language, issues related to local language identity, religious identity, colonialism, violence, and law enforcement based on the Ghanaian context. The facilitators were trained on how to integrate these socio-political issues into their delivery on Nyansapo while staying true to the key components of the 3MV intervention. The team was also trained on how to use recorders, iPad, and other materials to collect data from participants. They were also trained to facilitate group cohesion, and remain focused on fundamental intervention elements, as well as to conduct intervention sessions.

\section{Phase 8: Testing}

The Testing phase includes a pilot test of the adapted intervention (Sullivan et al., 2014).

Procedures and findings. To assess the primary study outcomes, quantitative data were collected from study participants at baseline and postintervention. Participants also completed postintervention focus groups which were audio-recorded and transcribed. Data were also obtained from written staff debriefings. For the pre-and postintervention surveys, each participant completed a survey with the aid of an iPad before departure to the retreat venue or before partaking in the activities scheduled for the session. Each participant also completed a survey after completing the session activities before leaving the retreat location. Additionally, a sample of participants reported to the office of the host organization to complete a oneweek post-intervention survey and a focus group discussion. The survey focused on several parts of MSM life in Ghana and sexual health or support groups. The first part of the survey gathered demographic information of participants; relationship status, ethnicity, education, approximate individual income, and sexual orientation or attraction.

The second part collected information on (1) sexual activities of participants; episodes and reasons for vaginal, anal, and oral sex, and the openness of sexual activities; (2) HIV and STI testing and sexual risk behaviors; HIV status, episode of HIV and STI testing and concerns about infections, condom use during anal, oral and vaginal sex, new sexual partners and practice of safe sex; (3) participant understanding of risk concerns, various types of STIs and their association to contracting others STIs and HIV, use of condoms among men of different sexual roles such as tops and bottoms; (4) interpersonal relationships; comfort, demeanor, acceptance, and influence if 
around peers, perceived gender physical appearance and roles, stereotypes, stigma, gendernonconforming behaviors and compromises; (5) experience of direct or indirect violence; physical harassment episode, beating due to sexuality or gender-non conforming behavior, rejection by family, loss of friends and associates, harassment from law enforcement, housing or accommodation issues, employment issues; (6) HIV stigma; rejection of people living with HIV, by family and friends, perception of shame associated to HIV, perception of bad behavior on PLHIV, perception of guilt, perception of religious sins; and (7) gender roles; perceived male and female social, economic, sexual, household chores and family responsibilities, gender and marital based violence, promiscuity among married couples. The post intervention surveys also asked intention evaluation specific questions focused on the expertise of facilitators, receptivity and response to questions, discussion of sensitive topics, group dynamics and facilitation, listening, comfortability with topics and inclusive learning environment, compassion, and relatability to participants. On the materials used for discussions, the survey gathered information on the helpfulness and usefulness of materials. Participants also reported via the focus groups, their overall thoughts on the impact of the intervention on their perception and knowledge of the content area and their intent of utilization of lessons learned from the intervention. The results from the study surveys and focus groups were reported elsewhere (Abubakari et al., 2020).

Modification/action. Testing occurred via a parallel pilot and implementation strategy, in which the first application consisted of a true pilot and subsequent changes were made to the intervention as needed. Study outcomes have been reported elsewhere (Abubakari et al., 2010). Briefly, study findings indicated that the intervention was feasible and acceptable in the study context. In postintervention participant focus groups participants reported that future iterations of the program could be improved by continued check-ins from program staff, increased conversation regarding justice issues and LGBT rights, and using social media so that participants can have continued contact post-retreat.

Staff debriefings. Staff debriefings highlighted the importance of holding the retreats away from typical participant distractions. Staff described that some participants recommended increased opportunities for community building, such as sporting activities. However, others noted that a balance between intervention material and community-building was needed. Staff noted that some participants wanted to test for HIV immediately upon assessing their risk and that having such resources readily available may benefit participants. Staff indicated that participants asked for greater outside interaction, hence, the collaboration with a nurse to attend an intervention session to speak about treatment as prevention and STI transmission. Similarly, two MSM police who engage with PORSH attended a session to address discrimination, emphasize participants' rights, describe how to report abuses, and provide a safe space for participants to report issues safely.

\section{DISCUSSION}

In this paper, we describe the use of the ADAPT-ITT model in the adoption and adaptation of the 3MV with MSM in Ghana. Despite the existing disproportionate infection rates of HIV among MSM and its association with existing structural factors (such as criminalization and stigma against MSM), and individual-level factors (such as sex without a condom, and transactional sex) in Ghana and other sub-Saharan African countries, only a few scholars consider intervention as an approach to reducing HIV and STI risk among MSM in the country (Koblin et al., 2006; Baral et al., 2011; Cloete et al., 2013; Logie et al., 2012; Nelson et al., 2015; Park et al., 2013; Sabin et al., 2018). As such, in collaboration with community partners, we engaged MSM through the use of the ADAPT-ITT model (Table 1) to adapt the 3MV (Table 2) to address HIV and STD risk factors and contribute to reducing HIV infections (Abubakari et al., 2020).

Whereas some scholars used the ADAPT-ITT in implementing interventions on HIV, substance use, and domestic violence in other settings, our processes serve as an early example of a successfully implemented culturally grounded intervention in West Africa that could be replicated by other scholars looking to implement interventions to address key and hidden populations such as MSM in other highly stigmatized settings (Wingwood et al., 2011a; Wingwod et al., 2008; Druss et al., 2010; Satinsky et al., 2020). Some of the key successes of our implementation are due to our ability to maintain the goals of the ADAPT-ITT framework, identify $3 \mathrm{MV}$ as a suitable intervention for adaptation, modify the $3 \mathrm{MV}$ to fit the Ghanaian MSM cultural setting, maintain 
successful recruitment and retention rates, and ensure a safe and secure environment for implementation. These successes are also the result of our ability to collaborate with an MSM community-based organization at all stages of the implementation process.

The ADAPT-ITT model supports the appropriate adaption of interventions in the field of HIV and new populations while maintaining the theoretical premise and core components of the original efficacious intervention (Wingwood et al., 2008; Sullivan et al., 2014). As indicated in Tables 1 and 2, the $3 \mathrm{MV}$ was a good fit as it met the recommendation by the ADAPT-ITT for an adaptation of a CDC recommended intervention, and we did not have to change the goals of the $3 \mathrm{MV}$ or its key components (Wingwood et al., 2008; Sullivan et al., 2014). The $3 \mathrm{MV}$ met our goals of working with MSM to positively influence behaviors such as condom use, reduction in sexual partners, increase HIV and STD testing as well as address and contextualize sociopolitical issues such as criminalization and stigma in a safe setting (Abubakari et al., 2020).

Nonetheless, as observed by other implementers of the ADAPT-ITT, we made minor alterations to some of the contents of the intervention to ensure fit with the Ghanaian MSM and general cultural/historical settings (Wingwood et al., 2011a, Latham et al., 2010; Marhedfka et al., 2014; Sullivan et al., 2014; Craig et al., 2016; Audet et al., 2017; Bere et al., 2017; Cederbaum et al., 2014). One of the key elements of the original $3 \mathrm{MV}$ focuses on enhancing self-esteem related to racial identity and sexual behavior (Wingwood et al., 2009). However, reports from our key partners and previous studies identified from Ghana show that a large proportion of MSM in the country identify as bisexual or have occasional sexual intercourse with women for various reasons including stigma (Kushwaha et al., 2017; Ogunbajo et al., 2020). As such, we focused more on discussing bisexuality, as well as condom use for various forms of sex including anal and vaginal sex to cater to participant needs. Specifically, instead of focusing on risk associated with having sex with men, we sought to create an understanding of what it means to have sex with both men and women, and the type of risks involved in unprotected sex with either sexes. Our pre-intervention results also confirmed the need to look more into bisexuality as $71.9 \%$ of our 57 participants reported that they have sex with both men and women (Abubakari et al., 2020).

Additionally, unlike the original 3MV and other feasibility studies conducted in the context of African Americans in the United States, we had to reduce the emphasis on racial identities to focus on religious, language, ethnic, and or cultural diversities among the participants (Abubakari et al., 2020; Ogunbajo et al., 2020). As reported in our findings in this context, Ghana has several ethnic groups that were featured in our program (Abubakari et al., 2020). There were no conditions for racial disparities and or issues surrounding racial identities as the country is a Black nation. Instead, as documented in several studies, current Ghanaian laws that criminalize MSM activities and promote stigma originating from religious thought and inherited through colonization (Caroll \& Itaborahy, 2015; Dai-Kosi et al., 2016; Tettey, 2016; Tweneboah, 2018; Gyamerah et al., 2020). We insisted, therefore, on incorporating such history in our contextualization of the current Ghanaian understanding of sexuality and its impact on sexual identification. As shown in our findings reported earlier, such discussions promoted a strong grounding for understanding sexuality and the role of societal structures in creating narratives around sexuality (Abubakari et al., 2020).

To make it more practical, we included a historical site trip to the Elmina Castle in the central region of Ghana where we held the retreat. At the castle, participants received tours and listened to narratives on slavery, religion, and the influence of colonization on the current sociopolitical landscape of the country. The practical component strengthened the discussion and awakened or created awareness among participants who did not have a full understanding of the colonial history and its impacts on laws, norms, and values of the Ghanaian society. We included these changes in the manual during the production and training stages to ensure that facilitators understood and implemented each component of the 3MV.

As noted in several studies on key populations and particularly those in African countries, recruitment, retention, and safety concerns remain key in ensuring the success of studies, hence, a gateway to recruitment remains through MSM organizations and peer referrals (Muller et al., 2018; Van Loggerenber et al., 2008; Smith et al., 2009; Transactional Sex, 2020; 
Hunter et al., 2020). As such, our program had great success in the recruitment and retainment of participants due to the involvement of communitybased organizations that work with MSM in the country. Recruitment rates increased after the first retreat when the initial participants sent word out to other MSM to participate in the program. The driving factors as gathered in our findings in Abubakari et al., (2020) was our ability to ensure that we chose a location outside of central parts of the cities that provided a discreet and carefree environment where MSM were able to feel comfortable without judgment or imminent danger of attack (Abubakari et al., 2020). Also, we incorporated fun activities such as sports, swimming (we were located on a beach resort), dance events, and acting to enhance the enjoyment of participants. The most important for us was the key leadership role our partner organization took in the implementation of the program. PORSH took leadership at levels of the implementation, thus, providing participants a sense of belonging due to their familiarity with and trust of PORSH.

Whereas our findings reported in Abubakari et al., (2020) show strong potentials in improving sexual health through the reduction of risk factors (such as sex without a condom and a development of menu items), increases in service utilization (voluntary HIV testing), our study highlights some shortcomings concerning monitoring and supporting the sustenance of peer networks, behavioral changes and the need for a longitudinal evaluation of outcomes (Abubakari et al., 2020). Although our study helped in setting up peer networks to support individual efforts to maintain a positive attitude towards sexual identity, and sexual health, our model and modified intervention did not create a mechanism to continue to monitor and maintain these groups and to support the changing needs of sexual health practices among participants.

As shown by many studies, maintenance of social networks contributes to minimizing the negative effects of stigma and HIV-risk and encourages the use of HIV services (Hunter et al., 2020; Heckathorn et al., 1999; Helleringer \& Kohler, 2005). Our future work will look to incorporate sustainable practices to ensure continuity of program impact among participants. Also, we only evaluated the impact of the program one-week and one-month postevaluation, hence, we could not establish the longitudinal impact of the program. Future research will incorporate longitudinal strategies of monitoring and evaluating our program impacts to contribute to the current understanding of changes in participants and to inform current research trajectories. Nonetheless, our study strongly positions community participatory interventions such as the $3 \mathrm{MV}$ and the ADAPT-ITT framework as key tools to assessing, identifying, and adapting interventions that have a significant impact on positively influencing behavior and sexual health practices among hidden populations in highly stigmatized environments.

\section{REFERENCES}

Abubakari, G. M., Nelson, L. E., Ogunbajo, A., Boakye, F., Appiah, P., Odhiambo, A., Ting, S., Nanhua, Z., Ironyah, N., Adjei, S., Geoffrey, M., Akubakar, M., \& Torpey, K. (2020).

Implementation and evaluation of a culturally grounded group-based HIV prevention programme for men who have sex with men in Ghana. Global Public Health, 1-18. doi:10.1080/17441692.2020.1832555

Audet, C. M., Salato, J., Vermund, S. H., \& Amico, K. R. (2017). Adapting an adherence support workers intervention: Engaging traditional healers as adherence partners for persons enrolled in HIV care and treatment in rural Mozambique. Implementation Science: IS, 12(1), 50-50. doi:10.1186/s13012-017-0582-z

Baral, S., Burrell, E., Scheibe, A., Brown, B., Beyrer, C., \& Bekker, L. (2011). HIV risk and associations of HIV infection among men who have sex with men in peri-urban Cape Town, South Africa.

BMC Public Health, 11(1), 766-766.

doi:10.1186/1471-2458-11-766

Bere, T., Nyamayaro, P., Magidson, J. F., Chibanda, D., Chingono, A., Munjoma, R., Macpherson, K., Ndhlovu, C.E., O’Cleirigh, C., Kidia, K., Safre, S.A., \& Abas, M. (2017). Cultural adaptation of a cognitive-behavioural intervention to improve adherence to antiretroviral therapy among people living with HIV/AIDS in Zimbabwe: Nzira itsva. Journal of Health Psychology, 22(10), 1265-1276. doi:10.1177/1359105315626783

Card, J. J., Solomon, J., \& Cunningham, S. D. (2011). How to adapt effective programs for use in new contexts. Health Promotion Practice, 12(1), 2535. doi:10.1177/1524839909348592

Caroll, A., \& Itaborahy, L. (2015). State-sponsored homophobia: A world survey of laws: 
Criminalisation, protection and recognition of same-sex love. ILGA.

Cederbaum, J. A., Song, A., Hsu, H., Tucker, J. S., \& Wenzel, S. L. (2014). Adapting an evidencebased intervention for homeless women: Engaging the community in shared decisionmaking. Journal of Health Care for the Poor and Underserved, 25(4), 1552-1570. doi:10.1353/hpu.2014.0188

Chen, E. K., Reid, M. C., Parker, S. J., \& Pillemer, K. (2013). Tailoring evidence-based interventions for new populations: A method for program adaptation through community engagement. Evaluation \& the Health Professions, 36(1), 7392. doi:10.1177/0163278712442536

Cloete, A., Kalichman, S.C., \& Simbayi, L.C. (2013). Layered stigma and HIV/AIDS:

Experiences of men who have sex with men (MSM) in South Africa. In Stigma, discrimination and living with HIV/AIDS 2013 (pp. 259-269). Springer, Dordrecht.

Craig Rushing, S., \& Gardner, W. (2016). Native VOICES: Adapting a video-based sexual health intervention for American Indian teens and young adults using the ADAPT-ITT model. American Indian and Alaska Native Mental Health Research, 23(1), 24-46. doi:10.5820/aian.2301.2016.24

Dai-Kosi, A. D., Asamani, L., \& Adomako, B. (2016). Ghanaian perspectives on the present day dynamics of homosexuality. African Research Review, 10(5), 1. https://doi.org/10.4314/afrrev.v10i5.1

Druss, B. G., Zhao, L., Von Esenwein, S. A., Bona, J. R., Fricks, L., Jenkins-Tucker, S., Sterling, E., DiClemente, R., \& Lorig, K. (2010). The health and recovery peer (HARP) program: A peer-led intervention to improve medical selfmanagement for persons with serious mental illness. Schizophrenia Research, 118(1), 264-270. doi:10.1016/j.schres.2010.01.026

Escoffery, C., Lebow-Skelley, E., Haardoerfer, R., Boing, E., Udelson, H., Wood, R., Hartman, M., Fernandez, M.E., \& Mullen, P. D. (2018). A systematic review of adaptations of evidencebased public health interventions globally. Implementation Science: IS, 13(1), 125-125. doi:10.1186/s13012-018-0815-9

Escoffery, C., Lebow-Skelley, E., Udelson, H., Böing, E. A., Wood, R., Fernandez, M. E., \& Mullen, P. D. (2019). A scoping study of frameworks for adapting public health evidence-based interventions. Translational Behavioral Medicine, 9(1), 1-10. doi:10.1093/tbm/ibx067

Evans, M. G. B., Cloete, A., Zungu, N., \& Simbayi, L. C. (2016). HIV risk among men who have sex with men, women who have sex with women, lesbian, gay, bisexual and transgender populations in South Africa: A mini-review. The Open AIDS Journal, 10(1), 49-64. doi:10.2174/1874613601610010049

Ghana AIDS Commission (GAC). (2017). Ghana Men's Study -2017. Mapping and population size estimation (MPSE) and integrated biobehavioral surveillance survey (IBBSS) amongst men who have sex with men (MSM) in Ghana (Round II). Accra. Ghana. https://www.ghanaids.gov.gh/mcadmin/Upload s/Ghana\%20Men\%27s\%20Study\%20Report(2).p df

Ghana AIDS Commission. (2020). 2019 HIV Estimates and National Projections. https://www.ghanaids.gov.gh/mcadmin/Upload s/2019\%20National\%20and\%20Sub-

National\%20Estimates\%20and\%20Projections\% 20Dissemination\%2021.07.2020.pdf

Girault, P., Green, K., Clement, N. F., Rahman, Y. A. A., Adams, B., \& Wambugu, S. (2015). Piloting a social networks strategy to increase HIV testing and counseling among men who have sex with men in greater Accra and Ashanti region, Ghana. AIDS and Behavior, 19(11), 1990-2000. doi:10.1007/s10461-015-1069-z

Gyamerah, A. O., Taylor, K. D., Atuahene, K., Anarfi, J. K., Fletcher, M., Raymond, H. F., McFarland, W., \& Dodoo, F. N. (2020). Stigma, discrimination, violence, and HIV testing among men who have sex with men in four major cities in Ghana. AIDS Care, 32(8), 1036-1044. doi:10.1080/09540121.2020.1757020

Haynes, V., Escoffery, C., Wilkerson, C., Bell, R., \& Flowers, L. (2014). Adaptation of a cervical cancer education program for African Americans in the faith-based community, Atlanta, Georgia, 2012. Preventing Chronic Disease, 11, E67-E67. doi:10.5888/pcd11.130271

Heckathorn, D. D., Broadhead, R. S., Anthony, D. L., \& Weakliem, D. L. (1999). Aids and social networks: HIV prevention through network mobilization. Sociological Focus (Kent, Ohio), 32(2), 159-179. doi:10.1080/00380237.1999.10571133

Helleringer, S., \& Kohler, H. (2005). Social networks, perceptions of risk, and changing attitudes 
towards HIV/AIDS: New evidence from a longitudinal study using fixed-effects analysis. Population Studies, 59(3), 265-282. doi:10.1080/00324720500212230

Hunter, J., Van Blerk, L., \& Shand, W. (2020). The influence of peer relationships on young people's sexual health in Sub-Saharan African street contexts. Social Science \& Medicine (1982), 113285-113285.

doi:10.1016/j.socscimed.2020.113285

Hohmeier, K. C., Wheeler, J. S., Turner, K., Vick, J. S., Marchetti, M. L., Crain, J., \& Brookhart, A. (2019). Targeting adaptability to improve medication therapy management (MTM) implementation in community pharmacy. Implementation Science: IS, 14(1), 99-99. doi:10.1186/s13012-019-0946-7

Joint United Nations Programme on HIV/AIDS. (2014). Fast-track: Ending the AIDS epidemic by 2030. Geneva: UNAIDS. https://www.unaids.org/sites/default/files/medi a_asset/UNAIDS_FastTrack_highlights_en.pdf

Knight, K. R., Das, M., DeMicco, E., Raiford, J.L., Matheson, T., Shook, A., Antinez, E., Santos, G.M., Dadasovich, R., Dilley, J.W., Colfax, G.N., \& Herbst, J. H. (2014). A roadmap for adapting an evidence-based HIV prevention intervention: Personal cognitive counseling (PCC) for episodic substance-using men who have sex with men.

Prevention Science, 15(3), 364-375. doi:10.1007/s11121-013-0364-z

Koblin, B. A., Husnik, M. J., Colfax, G., Huang, Y., Madison, M., Mayer, K., Barresi, P.J., Coates, T.J., Chesney, M.A., \& Buchbinder, S. (2006). Risk factors for HIV infection among men who have sex with men. AIDS (London), 20(5), 731-739. doi:10.1097/01.aids.0000216374.61442.55

Kushwaha, S., Lalani, Y., Maina, G., Ogunbajo, A., Wilton, L., Agyarko-Poku, T., Adu-Sarkodie, Y., Boakye, F., Zhang, N., \& Nelson, L. E. (2017). "But the moment they find out that you are MSM...": A qualitative investigation of HIV prevention experiences among men who have sex with men (MSM) in Ghana's health care system. BMC Public Health, 17(1), 770-770. doi:10.1186/s12889-017-4799-110(1), 65-77. doi:10.2174/1874613601610010065

Latham, T. P., Sales, J. M., Boyce, L. S., Renfro, T. L., Wingood, G. M., DiClemente, R. J., \& Rose, E. (2010). Application of ADAPT-ITT: Adapting an evidence-based HIV prevention intervention for incarcerated African American adolescent females. Health Promotion Practice, 11(3_suppl), 53S-60S. doi:10.1177/1524839910361433

Logie, C. H., Newman, P. A., Chakrapani, V., \& Shunmugam, M. (2012). Adapting the minority stress model: Associations between gender nonconformity stigma, HIV-related stigma and depression among men who have sex with men in South India. Social Science \& Medicine (1982), 74(8), 1261-1268.

doi:10.1016/j.socscimed.2012.01.008

Marhefka, S. L., Buhi, E. R., Baldwin, J., Chen, H., Johnson, A., Lynn, V., \& Glueckauf, R. (2014). Effectiveness of Healthy Relationships VideoGroup-A Videoconferencing Group Intervention for Women Living with HIV: Preliminary Findings from a Randomized Controlled Trial. Telemedicine and e-Health, 20(2), 128-134.

https://doi.org/10.1089/tmj.2013.0072

Müller, A., Spencer, S., Meer, T., \& Daskilewicz, K. (2018). The no-go zone: A qualitative study of access to sexual and reproductive health services for sexual and gender minority adolescents in Southern Africa. Reproductive Health, 15(1), 1-15. doi:10.1186/s12978-0180462-2

Nelson, L.E., McMahon, J., Zhang N, Adu-Sarkodie Y, Mayer KH. (2016). Exploring HIV, same-sex and gender non-conformity stigmas and delays in HIV diagnosis, linkage and retention for MSM in Ghana. National Institute of Mental Health.

Nelson, L. E., Wilton, L., Agyarko-Poku, T., Zhang, N., Aluoch, M., Thach, C. T., Owiredu Hanson, S., \& Adu-Sarkodie, Y. (2015). The association of HIV stigma and HIV/STD knowledge with sexual risk behaviors among adolescent and adult men who have sex with men in Ghana, West Africa.

Research in Nursing \& Health, 38(3), 194-206. doi:10.1002/nur.21650

Nelson, L. E., Wilton, L., Agyarko-Poku, T., Zhang, N., Zou, Y., Aluoch, M., Apea, V., Hanson, S.O., \& Adu-Sarkodie, Y. (2015). Predictors of condom use among peer social networks of men who have sex with men in Ghana, West Africa. PloS One, 10(1), e0115504-e0115504. doi:10.1371/journal.pone.0115504

Ogunbajo, A., Kershaw, T., Kushwaha, S., Boakye, F., Wallace-Atiapah, N.D., \& Nelson, L. E. (2018). Barriers, motivators, and facilitators to engagement in HIV care among HIV-infected Ghanaian men who have sex with men (MSM). 
AIDS and Behavior, 22(3), 829-839. doi:10.1007/s10461-017-1806-6

Ogunbajo, A., Leblanc, N. M., Kushwaha, S., Boakye, F., Hanson, S., Smith, M. D. R., \& Nelson, L. E. (2020). Knowledge and acceptability of HIV preexposure prophylaxis (PrEP) among men who have sex with men (MSM) in Ghana. AIDS Care, 32(3), 330-336. doi:10.1080/09540121.2019.1675858

Pan, S., Sun, S., Li, X., Chen, J., Xiong, Y., He, Y., \& Pachankis, J. E. (2020). A pilot cultural adaptation of LGB-affirmative CBT for young chinese sexual minority men's mental and sexual health. Psychotherapy (Chicago, III.), doi:10.1037/pst0000318

Park, J. N., Papworth, E., Kassegne, S., Moukam, L., Billong, S. C., Macauley, I., Yomb, Y.R., Nkoume, N., Mondoleba, V., Eloundou, J., LeBreton, M., Tamoufe, U., Grosso, A., \& Baral, S. D. (2013). HIV prevalence and factors associated with HIV infection among men who have sex with men in Cameroon. Journal of the International AIDS Society, 16(SI), 18752-n/a. doi:10.7448/IAS.16.4.18752

Poku, N. K. (2016). HIV prevention: The key to ending AIDS by 2030. The Open AIDS Journal, 10(1), 6577. doi:10.2174/1874613601610010065

Sabin, L. L., Beard, J., Agyarko-Poku, T., DeSilva, M., Ashigbie, P., Segal, T., Esang, M., Asafo, M.K., Wondergem, P., Green, K., Wambugu, S., \& AduSarkodie, Y. (2018). "Too much sex and alcohol": Beliefs, attitudes, and behaviors of male adolescents and young men who have sex with men in Ghana. The Open AIDS Journal, 12(1), 6980. doi:10.2174/1874613601812010069

Saleh-Onoya, D., Braxton, N. D., Sifunda, S., Reddy, P., Ruiter, R., van den Borne, B., Walters, T.P., Lang, D., \& Wingood, G. M. (2008). SISTA South Africa: The adaptation of an efficacious HIV prevention trial conducted with AfricanAmerican women for isiXhosa-speaking South African women. SAHARA J: Journal of Social Aspects of HIV/AIDS Research Alliance, 5(4), 186191. doi:10.1080/17290376.2008.9724918

Satinsky, E. N., Doran, K., Felton, J. W., Kleinman, M., Dean, D., \& Magidson, J. F. (2020). Adapting a peer recovery coach-delivered behavioral activation intervention for problematic substance use in a medically underserved community in Baltimore City. PloS One, 15(1), e0228084-e0228084.

doi:10.1371/journal.pone.0228084
Smith, A. D., Dr, Tapsoba, P., MD, Peshu, N., MPH, Sanders, E. J., PhD, \& Jaffe, H. W., Prof. (2009). Men who have sex with men and HIV/AIDS in Sub-Saharan Africa. The Lancet (British Edition), 374(9687), 416-422. doi:10.1016/S01406736(09)61118-1

Sullivan, P. S., Stephenson, R., Grazter, B., Wingood, G., Diclemente, R., Allen, S., Hoff, C., Salazar, L., Scales, L., Montgomery, J., Schwartz, A., Barnes, J., \& Grabbe, K. (2014). Adaptation of the African couples HIV testing and counseling model for men who have sex with men in the United States: An application of the ADAPT-ITT framework. Springerplus, 3(1), 1-13. doi:10.1186/2193-1801-3-249

Tettey, W. J. (2016). Homosexuality, moral panic, and politicized homophobia in Ghana: Interrogating discourses of moral entrepreneurship in Ghanaian media: Homosexuality, moral panic, and politicized homophobia. Communication, Culture \& Critique, 9(1), 86-106. doi:10.1111/cccr.12132

Transactional sex is associated with income level and psychosocial health problems among gay and bisexual men (GBM) in Nigeria, Africa. (2020).

The Journal of Sex Research, 1-7. doi:10.1080/00224499.2020.1854649

Tweneboah, S., \& Kwame Nkrumah University of Science and Technology. (2018). religion, international human rights standards, and the politicisation of homosexuality in Ghana. African Journal of Gender and Religion, 24(2) doi:10.14426/ajgr.v24i2.49

Van Loggerenberg, F., Mlisana, K., Williamson, C., Auld, S. C., Morris, L., Gray, C. M., Abdool Karim, Q., Grober, A., Barnabas, N., Iriogbe, I., \& Abdool Karim, S.S, for the CAPRISA 002 Acute Infection Study Team. (2008). Establishing a cohort at high risk of HIV infection in South Africa: Challenges and experiences of the CAPRISA 002 acute infection study. PloS One, 3(4), e1954e1954. doi:10.1371/journal.pone.0001954

Wilton, L., Herbst, J. H., Coury-Doniger, P., Painter, T. M., English, G., Alvarez, M. E., Scahill, M., Robertson, M., Lucas, B., Johnson, W.D., \& Carey, J. W. (2009). Efficacy of an HIV/STI prevention intervention for black men who have sex with men: Findings from the many men, many voices (3MV) project. AIDS and Behavior, 13(3), 532-544. doi:10.1007/s10461-009-9529-y

Wingwood, G. M., Diclemente, R. J., Stallworth, J., Purcell, D. W., Jean, R., Villamizar, K., Er, D.J., 
Devarona, M., Taveras, J., Painter, T.M., Lang, D.L., Hardin, J.W., \& Ullah, E. (2011a). Efficacy of a health educator-delivered HIV prevention intervention for Latina women: A randomized controlled trial. American Journal of Public Health (1971), 101(12), 2245-2252. doi:10.2105/AJPH.2011.300340

Wingood, G. M., \& DiClemente, R. J. (2008). The ADAPT-ITT model: A novel method of adapting evidence-based HIV interventions. Journal of Acquired Immune Deficiency Syndromes (1999), 47 Suppl 1, The First National Scientific Meeting of the Social and Behavioral Science Research Network (Supplement 1), S40-S46. doi:10.1097/QAI.0b013e3181605df1

Wingwood, G. M., Simpson-Robinson, L., Braxton, N. D., \& Rainford, J. L. (2011b). Design of a faithbased HIV intervention: Successful collaboration between a university and a church. Health Promotion Practice, 12(6), 823-831. doi:10.1177/1524839910372039 
Table 1: ADAPT-ITT phases, activities and modifications

\begin{tabular}{|c|c|c|c|}
\hline \multirow{2}{*}{\multicolumn{2}{|c|}{$\begin{array}{l}\text { Activities } \\
\text { ADAPT-IT Phase One: Assessment }\end{array}$}} & Procedures/Findings & Modifications/Actions \\
\hline & & \\
\hline $\begin{array}{l}\text { Content } \\
\text { - Prior Research } \\
\text { - Feedback from } \\
\text { Community organization } \\
\text { on the need for a } \\
\text { comprehensive sexual } \\
\text { health and social } \\
\text { intervention that targets } \\
\text { not just sexual behavior } \\
\text { but sexual identities and } \\
\text { related risk } \\
\text { Capacity } \\
\text { Assessment of the } \\
\text { capacity of the } \\
\text { organization }\end{array}$ & $\begin{array}{l}\bullet \\
\bullet \\
\bullet \\
\bullet \\
\bullet \\
\bullet \\
\bullet \\
\bullet\end{array}$ & $\begin{array}{l}\text { Reviewed previous Men's Study data and other st } \\
\text { behavior or experiences among MSM in Ghana } \\
\text { MSM in Ghana have a disproportionate HIV preva } \\
\text { population. They have a higher risk of contracting } \\
\text { behaviors } \\
\text { Reports also show an existing HIV, same gender, and } \\
\text { MSM and community. } \\
\text { MSM in Ghana expressed the need for capacity buildi } \\
\text { A special need for understanding gender and sexualit } \\
\text { Assessed staffing, and knowledge on the subject ma } \\
\text { host the program, and to deliver the program. } \\
\text { The organization had the capabilities to implement } \\
\text { staff body who were MSM themselves and understoc }\end{array}$ & $\begin{array}{l}\text { tudies on sexual health and HIV risk } \\
\text { lence rate compared to the general } \\
\text { new infections due to risky sexual } \\
\text { non-gender conforming stigma among } \\
\text { ing on sexual health and STI } \\
\text { ty identities and related risks } \\
\text { atter, ability to reach the population, } \\
\text { the projects. As they have an existing } \\
\text { od their lived experiences. }\end{array}$ \\
\hline $\begin{array}{l}\text { ADAPT-IT Phase Two: Decision } \\
\text { Formal and informal } \\
\text { discussions between } \\
\text { researchers and communi } \\
\text { based organizations on } \\
\text { contents of the } 3 \mathrm{MV}\end{array}$ & & $\begin{array}{l}\text { - Many Men, Many Voices chosen as the inte } \\
\text { adapted; although applicable, its content } \\
\text { American MSM experience hence the ne } \\
\text { modifications. }\end{array}$ & $\begin{array}{l}\text { ervention to be - No modifications were made to the goals of } \\
\text { ts portray the } \\
\text { eed for some }\end{array}$ \\
\hline \multicolumn{4}{|c|}{ ADAPT-IT Phase Three: Adaptation } \\
\hline $\begin{array}{l}\text { Adaptation } \\
\text { - Ghana team training on } \\
\text { 3MV } \\
\text { Reviewed } 3 \mathrm{MV} \text { manual } \\
\text { in conjunction with } \\
\text { Ghana team to identify } \\
\text { content areas for } \\
\text { modification. }\end{array}$ & & $\begin{array}{l}\text { Two selected trainers traveled from Ghana to the } \\
\text { United States for training on the various } \\
\text { components of the } 3 \mathrm{MV} \\
\text { Adaptations needed to address the intervention } \\
\text { name; tribalism; historical contexts related } \\
\text { to slavery and slave trade; colonialism and } \\
\text { religion; the increased need for discussions on } \\
\text { bisexuality }\end{array}$ & $\begin{array}{l}\text { - Content area alterations made to fit the Ghana cultural } \\
\text { setting. } \\
\text { - Focus on culture, ethnicity/tribalism, and religion. } \\
\text { - Incorporated tourism and history of Ghana and } \\
\text { colonial/slavery contexts } \\
\text { - Focus more on social issues such as law } \\
\text { enforcement, violence, } \\
\text { - Emphasis on bisexuality due to the high presence of } \\
\text { bisexuality in Ghana }\end{array}$ \\
\hline
\end{tabular}


- Production of Nyansapo manual and choosing of the host site
- Manual was created to fit the Ghana context

Assessment of sites to ensure their ability to deliver the intervention

- The site chosen was suitable to implement the intervention as it was safe and far away from participants' original communities.

\section{ADAPT-IT Phase Five: Topical Experts}
- Topic
experts were
participation
- Internal study team discussions
recruited for Phase 5 - During the study, three experts were identified; They include HIV scholars and community-level practitioners who engage with MSM

\section{ADAPT-IT Phase 6: Integration}
- Integration
- Experts confirmed that the adapted Nyansapo fit well with the $3 \mathrm{MV}$ goals and intent of the intervention

\section{ADAPT-IT Phase 7: Training}

- Training - 3-day training for the project team was held with the facilitator and the lead investigator leading the topics. The team was taken through how to use recorders, iPad in collecting data from participants. They were also taught how to handle difficult participants and most importantly to remain focused and act professionally.

- Co-facilitators and assistances were trained by the trainers who underwent ToTs in Denver

- The study taking place in a retreat center for maximum concentration from participants

- Training of Co-facilitators and assistance as part of the adaptation process. This was to ensure buy-in and engagement.

Participation of the PI to ensure the training was a success.

\section{ADAPT-IT Phase 8: Testing}

- Pilot - Staff debriefing sessions and post-intervention focus group discussions were conducted

testing - Hold the retreats away from typical participant distractions

of the - Some participants recommended increased opportunity for community building, such as sporting activities; interven however, others noted that a balance between intervention material and community-building is needed

tion

- Some participants wanted to test for HIV immediately upon assessing their risk

- $\quad$ Outside interactions with a nurse (e.g., discussion HIV testing) and police (e.g. to address human rights) were helpful

- Graduation certification were included to add merit to the training

- Languages familiar to the Ghanaian MSM were incorporated to ensure reach to participants

- No modifications were made at this point, but data were summarized to improve future delivery 
Table 2: 3MV sessions and adaptations undertaken for implementation

\begin{tabular}{|c|c|}
\hline \multicolumn{2}{|l|}{ Core intervention elements } \\
\hline Manual Content & Adaptation \\
\hline $\begin{array}{l}\text { 1) Enhance self-esteem related to racial identity and sexual behavior. } \\
\text { 2) Educate clients about HIV risk and sensitize to personal risk. } \\
\text { 3) Educate clients about interactions between HIV and other sexually transmitted diseases } \\
\text { and sensitize to personal risk. } \\
\text { 4) Develop risk reduction strategies. } \\
\text { 5) Build a menu of behavioral options for HIV and other STD risk reduction, including those } \\
\text { for individuals and those requiring partner involvement. } \\
\text { 6) Train in risk reduction behavioral skills. } \\
\text { 7) Enhance self-efficacy related to behavioral skills. } \\
\text { 8) Train in partner communication and negotiation. } \\
\text { 9) Provide social support and relapse prevention. }\end{array}$ & $\begin{array}{l}\text { - The program maintained all components except a minor } \\
\text { alteration to core number 1, to focus on ethnic, and } \\
\text { religious identities of participants and to highlight the } \\
\text { impact of colonialism and religion and how it contributed } \\
\text { to shaping the current anti-LGBTQ } \\
\text { - Historical contexts and a field trip component associated } \\
\text { with slavery and slave trade; colonialism and religion were } \\
\text { initiated before the retreat to create the background for } \\
\text { discussion } \\
\text { The name of the intervention was changed to Nyansapo, } \\
\text { meaning wisdom/streetwise in the Ghanaian context }\end{array}$ \\
\hline \multicolumn{2}{|l|}{ The Seven Sessions } \\
\hline Manual Content & Adaptation \\
\hline $\begin{array}{l}\text { 1. Black Gay Men and Dual Identity. The overall goal of Session } 1 \text { is to increase clients' } \\
\text { understanding of how a unique combination of internal and external factors can affect } \\
\text { the HIV-related behaviors of black gay men and contribute to disproportionately high } \\
\text { rates of HIV and other STDs and introduce clients to biomedical advances in HIV } \\
\text { prevention. }\end{array}$ & $\begin{array}{l}\text { - In addition to discussing HIV and STD among gay men, the } \\
\text { Nyansapo project also emphasized bisexuality and other } \\
\text { men who have sex with men because many men in Ghana } \\
\text { who have sex with men also have sex with women }\end{array}$ \\
\hline $\begin{array}{l}\text { 2. STD/HIV Prevention for Black Gay Men-The Roles and Risks for Tops and Bottoms. } \\
\text { One purpose of Session } 2 \text { is to provide basic information about transmission, symptoms, } \\
\text { testing, vaccines, and treatment of STDs and how STDs increase the chance of HIV } \\
\text { infection for black MSM. Further information about how HIV, PrEP, PEP, and HIV } \\
\text { treatment work to reduce transmission will be discussed. A second purpose is to } \\
\text { introduce the concept of Tops and Bottoms and discuss how sexual position affects the } \\
\text { chance of getting an STD and HIV. The session provides clients with the information they } \\
\text { need to build their menu of options for STD/HIV prevention in Session } 3 \text {. }\end{array}$ & $\begin{array}{l}\text { - In addition to the primary aim of the session, the risk } \\
\text { associated with having sex with women was also discussed } \\
\text { to ensure safe practices for those who have sex with both } \\
\text { men and women }\end{array}$ \\
\hline $\begin{array}{l}\text { 3. STD/HIV Risk Assessment and Prevention Options. The purpose of Session } 3 \text { is to } \\
\text { understand all the factors the determine risk of getting HIV or another STD and to } \\
\text { discuss and explore STD/HIV prevention and harm reduction options while increasing } \\
\text { clients' perception of their own risk and susceptibility to STDs/HIV. }\end{array}$ & - We maintained the content of this session \\
\hline $\begin{array}{l}\text { 4. Intentions to Act and Capacity for Change. The purpose of Session } 4 \text { is to help clients } \\
\text { understand that behavior change often occurs in stages and that addressing }\end{array}$ & - We maintained the content of this session \\
\hline
\end{tabular}


ambivalence and barriers to change is the first step toward fewer risk behaviors or toward more health promotion behaviors. Clients will identify a behavior they want to change and will develop a plan for changing that behavior.

5. Relationship Issues-Partner Selection, Communication, And Negotiation of Roles for Black Gay Men. The purpose of Session 5 is to discuss different kinds of power and power dynamics clients have observed in intimate relationships while growing up, and how the roles of Tops and Bottoms and Versatile are defined for black gay men in any type of intimate relationship, whether sexual or romantic. Another purpose of Session 5 is to discuss partner communication and negotiation.

6. Social Support and Problem Solving to Maintain Change. The purpose of Session 6 is to build clients' skills to use condoms, communicate, and negotiate with partners, and prevent and respond to relapse when it occurs.

7. Building Bridges and Community. The purpose of Session 7 is to provide clients with an opportunity to discuss their Many Men, Many Voices (3MV) experience and identify what resources they need to continue their behavior change option(s).

- Here, the emphasis was placed on the Ghanaian cultural setting of patriarchy and a discussion of gendered roles for men and women and then contextualizing it with expectations in same-sex relations and bisexual partners among the participants

- We maintained the content of this session

- We maintained the content of this session 